\title{
DIAGNOSTIC STUDY OF DIABATIC HEATING AND GENERATION OF KINETIC ENERGY DURING INTERACTION BETWEEN TWO EXTRATROPICAL CYCLONIC SYSTEMS: CASE STUDY
}

\author{
A. Abdeldym ${ }^{1}$, Mostafa Morsy, Tarek Sayad and H. Abdel Basset
}

Astronomy and Meteorology Department, Faculty of Science, Al-Azhar University, Cairo, Egypt. Corresponding Author: abdallh905@azhar.edu.eg, morsy@azhar.edu.eg, ta_sayad@azhar.edu.eg, heshmatm@yahoo.com

\begin{abstract}
This research aims to study and discuss the diabatic heating at the different isobaric levels during interaction between mid-latitude (southward extension of $500 \mathrm{hPa}$ trough) and extra-tropical (northward extension of Sudan monsoon low) cyclones over Egypt and east Mediterranean during the period 3-6 November 2015. Also, relationship between diabatic heating and kinetic energy generation were illustrated. The cyclogenesis of this case is associated with maximum heavy rainfall over northern part of Egypt during growth stage (4-5 November). Throughout the life cycle of cyclone, the vertical advection term $(\omega(\partial \mathrm{T} / \partial \mathrm{P}))$ is the significant term that plays an important role in diabatic heating calculation and opposite to adiabatic term $(-\omega(\alpha / \mathrm{Cp}))$. The largest contribution of the horizontal cold advection occurs during the pre-storm stage, while the largest warm advection occurs during the growth stage. Finally, it is found also that the area of diabatic cooling (heating) is synchronized with destruction (generation) of kinetic energy.
\end{abstract}

Keywords: diabatic heating: heavy rainstorm; Red Sea Trough; generation of kinetic energy..

\section{INTRODUCTION}

Sensible, latent, and radiative heat fluxes are considered as primary heating for the earth's atmosphere from below. Atmospheric diabatic heating is mostly related to flux divergence and water phase change and it is considered as one of the most important forces that drive atmospheric circulation. The first approximation that determines diabatic heating profiles depends on water phase changes due to vertical motions in microphysical processes. Generally in the depth of the atmospheric column, the convective diabatic heating is usually positive, while near the surface it is sometimes negative due to the effects of evaporative cooling.

Diabatic heating is, however, an elusive quantity, observationally. The elusiveness because the direct observational measurement of diabatic heating profiles is difficult. As a result of atmospheric heating cannot be directly measured and must be estimated indirectly from other variables. Generally, there are two approaches for diabatic heating evaluation, as reviewed by Kasahara and Mizzi [1]. The first one is the physical approach which computes the diabatic heating directly in terms of models and various physical processes parameterizations. The second is the dynamical approach obtains the diabatic heating through the residual method of the thermodynamic energy equation. Either approach has some limitations and deficiencies.

The horizontal temperature advection works in the opposite way of adiabatic heating $[2,3]$. Thus, the diabatic heating is roughly equivalent to the residual of two significant terms in the thermodynamic equation. Estimating the diabatic heating in the form of the thermodynamic equation in isobaric coordinates is affected by the method of vertical motion $(\omega)$ estimation. Kasahara and Mizzi [1] demonstrated the feasibility of employing the Isobaric Thermodynamic Method with the $\omega$ field generated by the kinematic method to estimate the global diabatic heating.

Several authors have attempted to diagnose global or hemispheric and local diabatic heating as a residual of the thermodynamic equation [1, 4-9]. Mapes and Houze [10] use observations of aircraft radars to estimate the vertical profiles of mesoscale diabatic heating, while Mather et al. [11] and Schumacher et al. [12] used the ground radars for this purpose. Because of radars observations are logistically 
challenging and very expensive, the vertical profile of diabatic heating is mostly estimated as a residual of the heat budget based on the developed technique by Yanai et al. [13] and practiced by many authors [e.g., 14-16].

The Extra-tropical (mid-latitude) cyclones system gets most of their energy from baroclinic instability and this energy often distributed over larger areas [17]. Extra-tropical cyclones require a baroclinic zone to develop and associated with strong horizontal temperature contrasts and upper-level wind field perturbation especially in winter. Extratropical cyclones are more pronounced over water than land among release of latent heat due to water vapor condensation [17]. Therefore, the Extra-tropical cyclones can be diagnosed by examining their energy sources, sinks, and transformations. The thermal field energetic properties, particularly as related to the diabatic heating in case of extra-tropical cyclones, have also been analyzed [18-21]. Investigations by Vincent [21] suggest that, of these heating components, latent heat release is the most significant in extratropical cyclones over continental regions, particularly in the cyclone's mature stage.

The disturbances of Extra-tropical cyclones in mid-latitude or in northern hemisphere during autumn, winter and spring can intrude into the Middle East. The northward extension of Sudan Monsoon Low trough from tropics over equatorial Africa region across the Red Sea is usually known as Red Sea Trough (RST) [22-25]. Extreme precipitation events in arid and semiarid subtropical regions often result from tropical-extratropical interactions. In subtropical regions such as southwestern the North America, the Levant, Pakistan, northwestern Africa, and South Africa, the dynamics of such extreme events has been investigated in numerous studies [26-32].

The aim of the present study is to compute, discuss and analyze the diabatic heating in terms of the thermodynamic equation at the different isobaric levels during a case of interaction between middle latitude (extension of 500hPa trough) and extratropical cyclones (extension of Sudan monsoon low) which affected on the weather of Egypt over a limited area during the period from 3 to 6 November.

\section{DATA AND METHODOLOGY}

\subsection{Data}

Six-hourly European Center for Medium Range weather Forecasting (ECMWF) Reanalysis Interim dataset [33] for wind components (zonal (u) and meridional (v)) in $\mathrm{m} / \mathrm{sec}$, air temperature $(\mathrm{T})$ in ${ }^{\circ} \mathrm{C}$, and geopotential height $(\mathrm{Z})$ in gpm with $2.5^{\circ} \times 2.5^{\circ}$ horizontal resolution. These data were obtained to cover the area from $20^{\circ} \mathrm{W}$ to $80^{\circ} \mathrm{E}$ and from $0^{\circ}$ to $80^{\circ} \mathrm{N}$ at $1000,850,700,500,400,300$, 250, 200, 150 and $100 \mathrm{hPa}$ pressure levels during the period 3-6 November 2015.

\subsection{Diabatic heating calculation}

The first low of thermodynamic is written in the following form (Eq. 1)

$$
\dot{Q}=C_{p} \frac{d T}{d t}-\alpha \omega
$$

Where $\bar{Q}=\frac{d Q}{d t}$ is the rate of change of diabatic heating following the motion, $\mathrm{T}$ is temperature, $\alpha$ is specific volume, $C_{p}$ is specific heat at constant pressure, $\omega=\mathrm{dP} / \mathrm{dt}$ is vertical motion. By expanding temperature total change ( $\mathrm{dT} / \mathrm{dt}$ ), Equation (1) can be written as

$\dot{Q}=C_{p}\left[\frac{\partial T}{\partial t}+V \cdot \nabla T+\omega\left(\frac{\partial T}{\partial P}-\frac{\alpha T}{C_{p} P}\right)\right]$

Where, the diabatic heating change $(\dot{Q})$ depends on; local temperature changes $(\partial \mathrm{T} / \partial \mathrm{t})$; quasi-horizontal advection of temperature gradient $(\mathrm{V} . \nabla \mathrm{T})$; vertical temperature advection $(\omega \partial \mathrm{T} / \partial \mathrm{P})$; and adiabatic temperature changes associated with work done on the environment during vertical motion $(-\omega \alpha / \mathrm{Cp})$. The main processes that contribute to diabatic heating is the release of latent heat due to condensation of turbulent flux, water vapor and short-long wave radiations.

The diabatic heating change is calculated using Equation (2) at 0000 and 1200UTC along the period of case study. The local change, horizontal and vertical advection of temperature are computed using central finite difference at all pressure levels except at space and time boundaries where non-central finite differences were employed. The calculations of diabatic heating terms (Equation 2) were 
produced along the inner domain which extends from $20^{\circ} \mathrm{E}$ to $40^{\circ} \mathrm{E}$ and from $20^{\circ} \mathrm{N}$ to $45^{\circ} \mathrm{N}$

Vertical motion $(\omega)$ estimation using the kinematic method affects the diabatic heating. However, due to errors in horizontal divergence estimates, accumulation of error in $\omega$ occurs away from the bottom of the atmosphere. To remove this bias a pressure-weighted correction for $\omega$ was adopted following [34]. This technique was used to compute $\omega$ values at all grid point on all slandered isobaric levels and at the midpoint of each sub layer. Moreover, $\omega$ was initially set to zero at both top and bottom of the atmosphere. The $1 \mathrm{~W} \mathrm{Kg}^{-1}=86 \mathrm{~K}$ day $^{-1}$ transformation is used to convert heating rates per unit mass to daily heating.

\subsection{Kinetic energy generation}

The computational method applied in this study uses the local rate of change of kinetic energy that is expressed by Smith [35] and applied by many authors such as Smith [36], Ward and Smith [37] and Abdeldym et al. [38].

$$
\begin{aligned}
\frac{\partial K}{\partial t} \equiv \frac{1}{s g} \int_{0}^{P_{0}} \int_{S} \frac{\partial k}{\partial t} d s d P=-\frac{1}{s g} \int_{0}^{P_{0}} \int_{S} V \cdot \nabla \varphi d s d P \\
\quad-\frac{1}{s g} \int_{0}^{P_{0}} \int_{S} \nabla \cdot(V k) d s d P-\frac{1}{s g} \int_{0}^{P_{0}} \int_{S} \frac{\partial(\omega k)}{\partial P} d s d P-D(k)(3)
\end{aligned}
$$

Where the area of computational domain is $\mathrm{S}$, the gravitational acceleration is $\mathrm{g}$, and $\mathrm{Po}$ is the surface pressure. It is noticed that local rate change of kinetic energy depends on the generation of kinetic energy as first term on the right hand side of Equation (3), the conversions of horizontal and vertical flux of kinetic energy as second and third terms and finally on the dissipation term (last term).

\section{SYNOPTIC SITUATION}

The common cyclogenesis pattern over east Mediterranean occurs typically throughout the interaction between upper air trough as southward extension of extra-tropical cyclone and the northward extension of the Sudan monsoon low as Red Sea Trough (RST).

The synoptic situation for this case has been analyzed and discussed in details by Abdeldym et al. [38]. They divided the life cycle of cyclone into three different stages as; the onset of cyclone which refers to pre- cyclonic stage (3 November 2015); while the second period represent growth stage (4-5 November 2015); finally, the last period is decay stage (6 November 2015). Their results demonstrated that the strong interaction between the RST from the tropical region and the upper air trough from middle latitude region leads to more atmospheric instability associated with thunder activity and heavy rainfall exceeds $100 \mathrm{~mm}$.

\section{DIAGNOSTIC STUDY OF DIABATIC HEATING}

\subsection{Time development}

The assessment of the diabatic heating in the isobaric thermodynamic method terms allows the individual contribution of each effect to be investigated [39]. The thermodynamic equation Eq. (2) is calculated on the domain $\left(20^{\circ}-40^{\circ} \mathrm{E}\right.$ and $\left.20^{\circ}-45^{\circ} \mathrm{N}\right)$ which encloses our cyclone during its life cycle.

Table 1 shows the vertical average for areamean from 1000 to $100 \mathrm{hPa}$ for all terms of thermodynamic equation every 12 hours. It is indicated from Table 1 that:

1. The values of local temperature changes $(\partial \mathrm{T} / \partial \mathrm{t})$ are smaller in magnitude than other terms; therefore the diabatic heating term is mathematically balanced by the horizontal and vertical temperature advection and the adiabatic temperature changes.

Table 1.Vertical mean (1000 to $100 \mathrm{mb}$ ) of areamean for thermodynamical equation terms for

\begin{tabular}{|c|c|c|c|c|c|}
\hline $\begin{array}{c}\text { Datel } \\
\text { time }\end{array}$ & $Q$ & $\partial \Gamma / \partial$ & $V . \nabla T$ & $\omega(\partial T / \partial P)$ & $-\omega(\alpha / C p)$ \\
\hline \multicolumn{6}{|c|}{ Pre-storm stage } \\
\hline $3 / 00$ & -7.97 & -0.28 & -11.09 & -2.75 & 6.15 \\
\hline $3 / 12$ & -5.24 & -0.21 & -7.92 & -1.94 & 4.83 \\
\hline $4 / 00$ & -0.34 & 0.03 & -3.11 & -2.3 & 5.04 \\
\hline \multicolumn{6}{|c|}{ Growth stage } \\
\hline $4 / 12$ & 4.14 & 0.23 & 3.46 & -0.25 & 0.7 \\
\hline $5 / 00$ & 5.88 & 0.3 & 4.89 & -1.52 & 2.21 \\
\hline $5 / 12$ & 9.53 & 0.29 & 4.44 & -4.62 & 9.4 \\
\hline \multicolumn{6}{|c|}{ Decay stage } \\
\hline $6 / 00$ & 5.49 & 0.34 & 1.55 & -3.26 & 6.86 \\
\hline $6 / 12$ & 8.22 & 0.31 & 1.22 & -6.93 & 13.62 \\
\hline
\end{tabular}
cyclone. Units are $\mathrm{K}(\mathbf{d a y})^{-1}$

2. The adiabatic temperature term is the dominant term of heat except at $12 \mathrm{Z04}$ November at the growth period, is robustly correlated with the upward vertical motion in the computational domain. 
3. The largest horizontal advection cooling and heating occurs during pre-storm and growth stages, respectively. In addition, the diabatic heating and cooling is strongly associated with horizontal advection into the computational domain.

4. The adiabatic term is the dominant term and often increases diabatic heating during all storm stages especially at the last three time or decay period.

5. The vertical advection term produces diabatic cooling throughout the period of this cyclone that is permanently working against the adiabatic temperature term.

6. Generally, rising motion produces heating due to adiabatic term and cooling due to vertical advection term and vice versa.

\subsection{Time-pressure variations}

The thermodynamic equation in isobaric coordinates provides a way to visualize how the thermodynamic equation terms are balanced between each other. The time pressure cross section (variation) of each term in the thermodynamic equation (Eq. 2) throughout the life cycle of this cyclone is obtained in figure 1 .

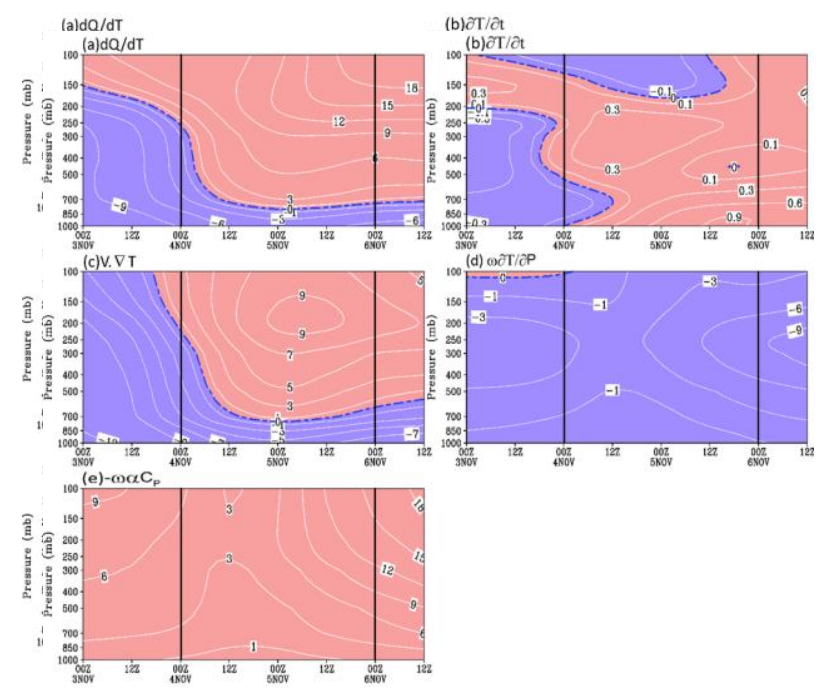

Figure 1. Time height cross section of a) diabatic heating, b) local temperature change, c) horizontal advection of temperature, d) vertical temperature advection and e) adiabatic heating. Unit: $K(\text { day })^{-1}$

The local temperature change has very small contributions to the diabatic heating changes comparing with all the other terms as shown in Figure 1b. It is denoted that there is a local decrease (increase) of temperature during the Pre-storm (Growth) period and reversed above $200 \mathrm{hPa}$, while the local temperature decreases in the layer between 850 and $500 \mathrm{hPa}$ during the period 00Z04-12Z04. Furthermore, the decay period characterized by a local increase in temperature at all levels. Also, from Figure $1 \mathrm{~b}$ one can notice that there are two maximum increase of local temperature in the Growth period; the first one appears at the layer $300-250 \mathrm{hPa}$ that may be due to the weakness and retraction of the polar jet and strengthening the subtropical jet [38]; the second (highest) one is noticed through the layer $1000-850 \mathrm{hPa}$ may be related to increase the adiabatic heating term and decrease the vertical advection term in this period.

The straight temperature advection (V.VT) is demonstrated in Figure 5c, where the cold advection occurs during the pre-storm period at all levels with maximum cooling between 1000 and $700 \mathrm{hPa}$ especially at the first time. In the growth and decay stages, the horizontal warm advection dominates within the levels from 850 up to $100 \mathrm{hPa}$ and the cold advection dominates at low levels below $850 \mathrm{hPa}$ in growth stage and below $700 \mathrm{hPa}$ in decay stage. The maximum heating of V.VT occurs during the period 12Z04-12Z05 (maximum rainy period) at the layer between 300 and $150 \mathrm{hPa}$ that is associated with strengthening of subtropical jet stream. The interesting feature that should be noted from V.VT term is the occurrence of maximum cold advection near the surface throughout all stages. Figure 1d shows the vertical advection term $(\omega \partial \mathrm{T} / \partial \mathrm{P})$ pattern, which leads to cooling throughout the three stages except little heating in the pre-storm stage at upper levels (150-100 $\mathrm{hPa})$. The maximum cold contribution of the vertical advection term detected at the end of growth stage (00Z0512Z06) especially in the layer from 500 to 150 $\mathrm{hPa}$. The adiabatic term $(-\omega \alpha / \mathrm{CP})$ is shown in Figure 1e leads to heating during the three stages at all levels. The maximum heating by the adiabatic term noticed between 00Z05 to $00 \mathrm{Z} 06$ especially above $500 \mathrm{hPa}$. The adiabatic term numerically almost cancel the vertical advection term and work in an opposite way with strong negatively correlation in patterns particularly when viewed in the time pressure cross section. Lastly, the diabatic heating term is illustrated in Figure 1a, where it is exaggerated by the horizontal advection term more than the extra terms. The per-storm period is distinguished by the diabatic cooling at all levels with maximum on 00Z03. A pronounced 
heating exists during the growth and decay period at all levels above $850 \mathrm{hPa}$, while the maximum heating appears above $500 \mathrm{hPa}$ especially in the layer between 300 and 150 $\mathrm{hPa}$ during the period from mid of growth stage to the end of the decay stage. While the diabatic cooling appears on the layer from 1000 to 850 $\mathrm{hPa}$ in all period of this cyclone with maximum cooling during the pre-storm period and minimum cooling during the growth stage which is mainly due to the latent heat release accompanied by maximum rainy period.

\subsection{Spatial Distribution}

The spatial distribution of diabatic heating is considered to examine the relationship between the prevailing synoptic features and the ensemble cyclogenesis. Figures 2 and 3 illustrate the spatial distribution of the diabatic heating rate and the vertical motion from $00 \mathrm{Z} 03$ to $12 \mathrm{Z} 06$ November 2015 at $850 \mathrm{hPa}$ respectively.
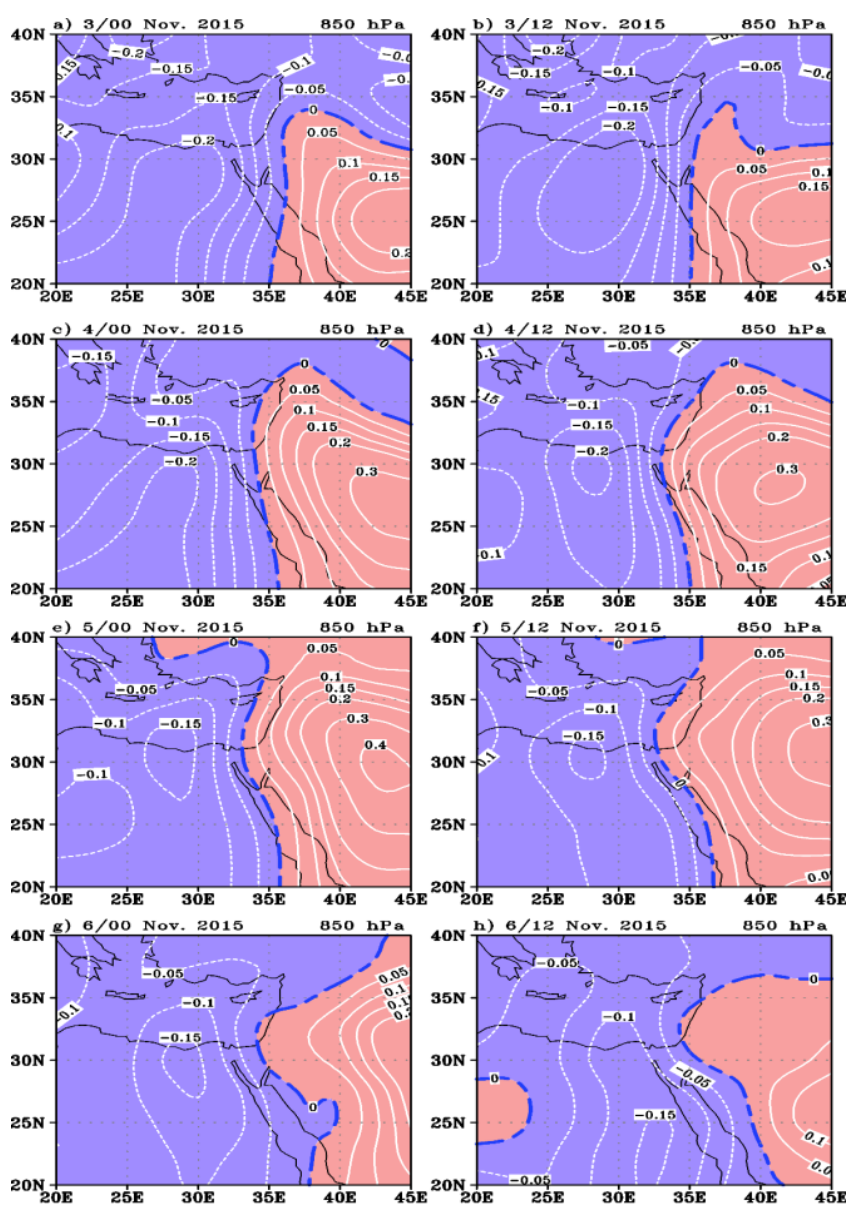

Figure 2. Horizontal distribution of diabatic heating rate at $850 \mathrm{hPa}$, positive values are solid lines and negative values are dashed lines, at $00 \mathrm{Z}$ and $12 \mathrm{Z}$ during 03-06 November 2015.
The diabatic warming and vertical movement at $850 \mathrm{hPa}$ is presented, because it clearly shows the area of baroclinicity at the middle atmosphere, where the other levels not shown. The pattern of diabatic warming during the life cycle of cyclone indicates that the cold sector dominates most of western part of the domain (west of $35^{\circ} \mathrm{E}$ ), while the warm sector prevails most of eastern part of the domain (east of $35^{\circ} \mathrm{E}$ ). In pre-storm period the cold sector (diabatic cooling; Figure 2) is covered by subtropical high pressure at 1000 and $850 \mathrm{hPa}$ [38] and associated with downward motion at the same levels (Figure 3), while the warm sector (diabatic heating; Figure 2) is accompanied by low pressure (RST) and upward motion (Figure 3). In other words, the diabatic heating behaves like warm advection from southeast with RST, and the diabatic cooling behaves like cold advection from northwest with the subtropical high pressure.

Therefore, in the vicinity of developing convection, the relative maximum and minimum values of diabatic warming is usually accompanied by rising and sinking motions respectively as clearly shown at $850 \mathrm{hPa}$ (Figure 3) and other levels (not shown).

With time increment (especially in growth stage) the diabatic heating and cooling variation over the computational domain, two main features are detected at 1000, 850, 700 and 500 $\mathrm{hPa}$. The first feature is the existence of maximum cooling at $1000 \mathrm{hPa}$ over the most of Mediterranean with the highest value of -0.5 $\mathrm{K} /$ day and the heating/cooling increase/ decrease with altitude up to $500 \mathrm{hPa}$. This maximum cooling appears to be related to the advection and penetration of the intense northwesterly cold arctic air across most of the Mediterranean and tends to decrease towards the southwestern of Red Sea. Another notable feature is the significant warm sector observed on Saudi Arabia with maximum heating (0.4 $\mathrm{K} /$ day) at $700 \mathrm{hPa}$ and temporarily moved eastward with intensification. At the maximum rainy period the cooling rate decreases and reaches its minimum value, while the heating rate increases and cover most of the computational domain. Furthermore, the heating rate values are much greater than the corresponding cooling rate values. The maximum temporal and spatial heating 
(occurred at 00Z05 November) was found to be accompanied by the maximum system deepening, where the movement of either diabatic heating or cooling pattern is strongly correlated with the movement of the cyclonic system. With the begin of the decay stage the pattern of diabatic cooling and heating sectors are changed, where the cyclone is moved eastward and become stationary vortex rotate over the east of Mediterranean and the subtropical jet is shifted northward and intensified.
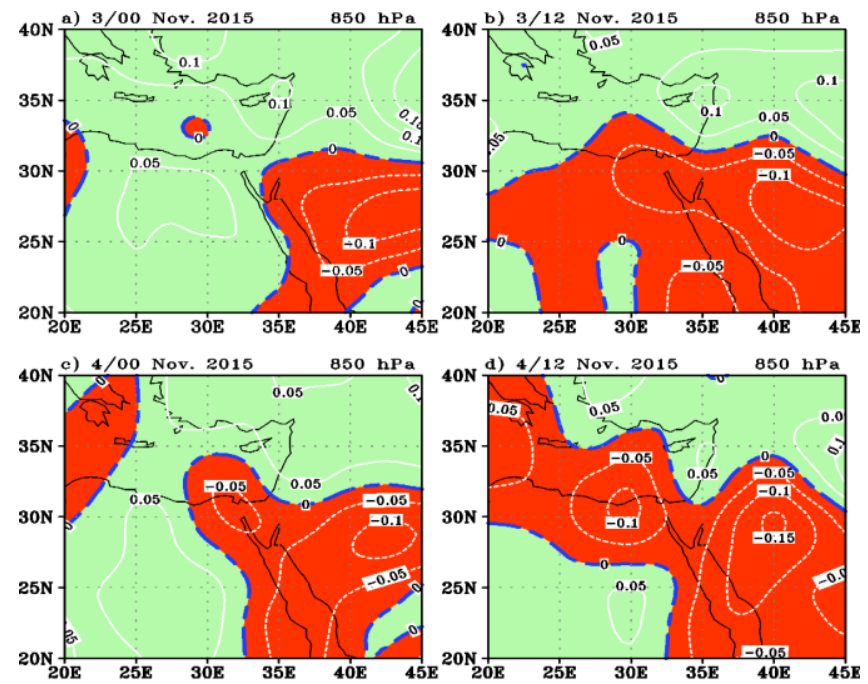

between 1000 and $100 \mathrm{hPa}$ in each day every 12 hours (Table 2). The analysis and discussion of kinetic energy generation for this case have been discussed in detail by Abdeldym et al. [38]. But in this study, it is sufficient to note that the cyclone life cycle can be described well using the generation term $(-V \cdot \nabla \varphi)$. Where, In the pre-storm stage this term acts as sinking of energy at the most levels (below $200 \mathrm{hPa}$ ) by conversion of kinetic to potential energy. Also, the magnitude of this term is an indication for a extensive and existence of imbalance in the mass and wind fields (Figure 4). In the growth stage of the cyclone the main source of energy is the generation term by converting potential energy to kinetic energy with highest values in the layer $200-100 \mathrm{hPa}$. Also it acts below 700 $\mathrm{hPa}$ as a weak sinking of energy particularly during the growth and decay stages. Above 500 $\mathrm{hPa}$ in the decay stage, this term $(-V . \nabla \phi)$ acts as a main energy source.

Table 2. Vertical mean of area average for kinetic energy generation for the cyclone $\left(\mathrm{Wm}^{2}{ }^{2}\right)$.

\begin{tabular}{|c|c|c|c|c|c|c|c|c|}
\hline Stage & \multicolumn{3}{|c|}{ Pre-storm } & \multicolumn{3}{c|}{ Growth } & \multicolumn{3}{c|}{ Decay } \\
\hline $\begin{array}{c}\text { Date/ } \\
\text { time }\end{array}$ & $3 / 00$ & $3 / 12$ & $4 / 00$ & $4 / 12$ & $5 / 00$ & $5 / 12$ & $6 / 00$ & $6 / 12$ \\
\hline$-V . \nabla \varphi$ & -35.38 & -28.15 & -2.44 & 14.28 & 24.65 & 23.55 & 18.88 & 13.93 \\
\hline
\end{tabular}
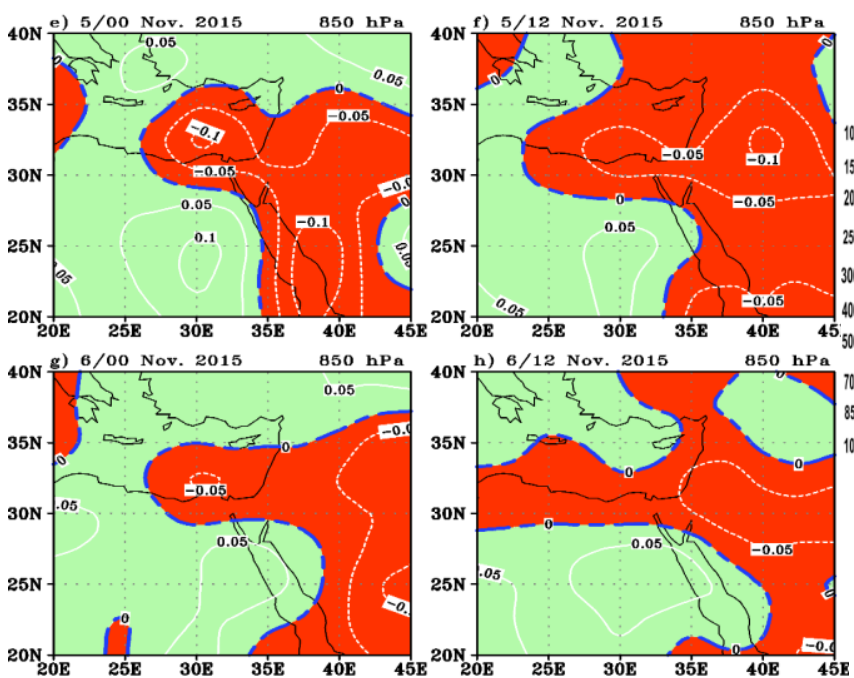

Figure 3. Vertical motion $\left(\mathrm{PaS}^{-1}\right)$ at $850 \mathrm{hPa}$; solid lines denote positive values and dashed lines denote negative values at $00 \mathrm{Z}$ and $12 \mathrm{Z}$ during 03-06 November 2015.

\section{Kinetic energy generation}

The kinetic energy generation term in equation (3) in the computational domain is calculated during the different stages of the cyclone. The vertical-mean of area average for the generation term is integrated in the layer

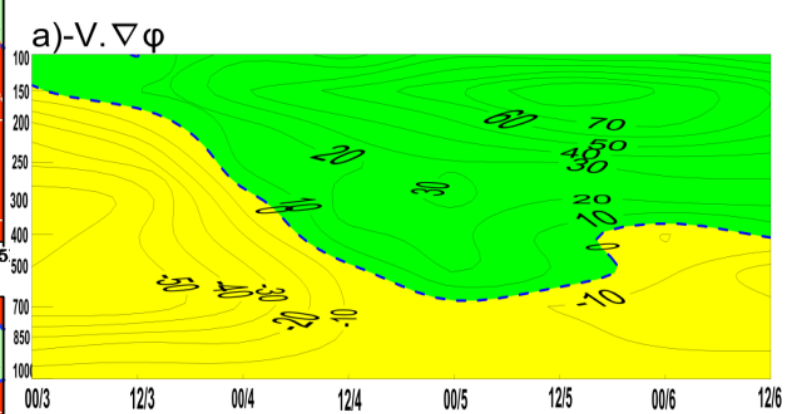

Figure 4. Time-Height cross sections of kinetic energy generation. Unit $\left.\mathrm{Wm}^{-2}(100 \mathrm{hPa})^{-1}\right)$.

\section{RELATIONSHIP BETWEEN DIABATIC HEATING AND KINETIC ENERGY GENERATION}

The Time-Height variation and spatial distribution of diabatic heating and kinetic energy generation is used to discuss and investigate their relationship during the life cycle of the cyclone. Following the TimeHeight variation of diabatic heating (Figure 1a) and the corresponding and kinetic energy generation (Figure 4), it is noticed that the 
negative of kinetic energy generation is associated with diabatic cooling and the positive generation is associated with heating. The movement of either diabatic heating or cooling pattern is strongly correlated with the movement of either positive or negative generation of kinetic energy and also with the cyclone movement.

A. Generally, the field of diabatic heating is closely related to the field of kinetic energy generation, where the area of diabatic cooling is associated with destruction of kinetic energy and the area of diabatic heating is associated with generation of kinetic energy.

B. The diabatic heating usually occurs in the cyclone's warm sector when the convection is most active.

C. The intensification and movement of the heating/cooling areas coincide significantly with those corresponding generation /destruction of kinetic energy.

D. Kinetic energy generation and diabatic heating increases as the cyclone system develops and decreases as the system starts to decay and reversed in the area of Kinetic energy destruction and diabatic cooling.

\section{CONCLUSION}

Study the diabatic heating during interaction between mid-latitude (southward extension of upper air trough) and extratropical (RST) cyclones over east Mediterranean and its relation to the kinetic energy generation during 3-6 November 2015. The RST and upper level troughs were amalgamated and developed that led to atmospheric instability associated with heavy rainfall over northern part of Egypt and east Mediterranean with maximum rainfall during 4-5 November (growth stage). The thermodynamic equation in isobaric coordinates is utilized to compute the diabatic heating. The diabatic warming is strongly correlated with the horizontal warm air advection during the cyclone life cycle into the computational domain. Also, it is concluded that the contribution of adiabatic term and the vertical temperature advection are opposite to each other, which create a strong negative correlation between their patterns. The local temperature changes term has very small contributions to the diabatic heating rates comparing with other terms.

The field of diabatic warming is closely related to the field of kinetic energy generation. Where, the area of diabatic cooling is associated with destruction of kinetic energy and the area of diabatic warming is associated with kinetic energy generation which usually occurs in the cyclone's warm sector since the convection is most active in this area. The intensification and movement of the heating /cooling areas coincide significantly with those corresponding of the generation/destruction of kinetic energy.

\section{REFERENCES}

[1] Kasahara, A., \& Mizzi, A. P. (1985). Preliminary evaluation of diabatic heating distribution from FGGE level $3 b$ analysis data.

[2] Wei, L. J., \& Johnson, W. E. (1985). Combining dependent tests with incomplete repeated measurements. Biometrika, 72(2), 359-364.

[3] Wei, M.-Y., T. K. Schaack and R. D. Selin, 1984: A quick comparison of diabatic heating rates between NMC III-a and ECMWF IIIb data sets for January 1979. U.S. Committee forGARP, Global Weather Experiment Newsletter, No. 4, USC-GARP, National Academy of Sciences, Washington, DC, 11-20.

[4] Geller, M. A., \& Avery, S. K. (1978). Northern Hemisphere distributions of diabatic heating in the troposphere derived from general circulation data. Monthly Weather Review, 106(5), 629-636.

[5] Lau, N. C. (1979). The observed structure of tropospheric stationary waves and the local balances of vorticity and heat. Journal of the Atmospheric Sciences, 36(6), 996-1016.

[6] Murakami, T., \& Ding, Y. H. (1982). Wind and temperature changes over Eurasia during the early summer of 1979. Journal of the Meteorological Society of Japan. Ser. II, 60(1), 183-196.

[7] Nitta, T. (1983). Observational study of heat sources over the eastern Tibetan Plateau during the summer monsoon. Journal of the Meteorological Society of Japan. Ser. II, 61(4), 590-605.

[8] Luo, H., \& Yanai, M. (1984). The large-scale circulation and heat sources over the Tibetan 
Plateau and surrounding areas during the early summer of 1979. Part II: Heat and moisture budgets. Monthly Weather Review, 112(5), 966-989.

[9] Chen, T. C., \& Baker, W. E. (1986). Global diabatic heating during FGGE SOP-1 and SOP-2. Monthly weather review, 114(12), 2578-2589.

[10] Mapes, B. E., \& Houze Jr, R. A. (1995). Diabatic divergence profiles in western Pacific mesoscale convective systems. Journal of the atmospheric sciences, 52(10), 1807-1828.

[11] Mather, J. H., McFarlane, S. A., Miller, M. A., \& Johnson, K. L. (2007). Cloud properties and associated radiative heating rates in the tropical western Pacific. Journal of Geophysical Research: Atmospheres, 112(D5).

[12] Schumacher, C., Houze Jr, R. A., \& Kraucunas, I. (2004). The tropical dynamical response to latent heating estimates derived from the TRMM precipitation radar. Journal of the Atmospheric Sciences, 61(12), 1341-1358.

[13] Yanai, M., Esbensen, S., \& Chu, J. H. (1973). Determination of bulk properties of tropical cloud clusters from large-scale heat and moisture budgets. Journal of the Atmospheric Sciences, 30(4), 611-627.

[14] Lin, X., \& Johnson, R. H. (1996). Heating, moistening, and rainfall over the western Pacific warm pool during TOGA COARE. Journal of the atmospheric sciences, 53(22), $3367-3383$.

[15] Zhang, M. H., \& Lin, J. L. (1997). Constrained variational analysis of sounding data based on column-integrated budgets of mass, heat, moisture, and momentum: Approach and application to ARM measurements. Journal of the atmospheric sciences, 54(11), 1503-1524.

[16] Abdel-Basset, H., Al-Khalaf, A. K., \& Albar, A. (2015). Diabatic processes and the generation of the low-level potential vorticity anomaly of a rainstorm in Saudi Arabia. Atmospheric and Climate Sciences, 5(3), 57887.

[17] Georgiev, C., Santurette, P., \& Maynard, K. (2016). Weather analysis and forecasting: Applying satellite water vapor imagery and potential vorticity analysis. Academic Press.

[18] Danard, M. B. (1964). On the influence of released latent heat on cyclone development. Journal of Applied Meteorology, 3(1), 27-37.

[19] Widger Jr, W. K. (1969). Radiative Generation of Eddy Available Potential Energyin
Extratropical Cyclones. Journal of the Atmospheric Sciences, 26(4), 647-647.

[20] Gall, R. L., \& Johnson, D. R. (1971). The generation of available potential energy by sensible heating: A case study. Tellus, 23(6), 465-482.

[21] Vincent, D. G., Pant, G. B., \& Edmon Jr, H. J. (1977). Generation of available potential energy of an extratropical cyclone system. Monthly Weather Review, 105(10), 12521265.

[22] El Fandi, M. G., 1946, "Baroclinic low Cyprus" Q. J. R. Meteorol. Soc., 72, 291-306.

[23] Alpert, P., Osetinsky, I., Ziv, B., \& Shafir, H. (2004a). Semi objective classification for daily synoptic systems: Application to the eastern Mediterranean climate change. International Journal of Climatology: A Journal of the Royal Meteorological Society, 24(8), 1001-1011.

[24] Alpert, P., Osetinsky, I., Ziv, B., \& Shafir, H. (2004b). A new seasons definition based on classified daily synoptic systems: an example for the eastern Mediterranean. International Journal of Climatology: A Journal of the Royal Meteorological Society, 24(8), 1013-1021.

[25] Tsvieli, Y., \& Zangvil, A. (2005). Synoptic climatological analysis of 'wet'and 'dry'Red Sea Troughs over Israel. International Journal of Climatology: A Journal of the Royal Meteorological Society, 25(15), 1997-2015.

[26] Knippertz, P., Fink, A. H., Reiner, A., \& Speth, P. (2003). Three late summer/early autumn cases of tropical-extratropical interactions causing precipitation in northwest Africa. Monthly Weather Review, 131(1), 116-135.

[27] Knippertz, P., \& Martin, J. E. (2005). Tropical plumes and extreme precipitation in subtropical and tropical West Africa. Quarterly Journal of the Royal Meteorological Society: A journal of the atmospheric sciences, applied meteorology and physical oceanography, 131(610), 2337-2365.

[28] Knippertz, P., \& Martin, J. E. (2007). A Pacific moisture conveyor belt and its relationship to a significant precipitation event in the semiarid southwestern United States. Weather and Forecasting, 22(1), 125-144.

[29] Ziv, B., Dayan, U., \& Sharon, D. (2005). A mid-winter, tropical extreme flood-producing storm in southern Israel: synoptic scale analysis. Meteorology and Atmospheric Physics, 88(1-2), 53-63. 
[30] Hart, N. C. G., Reason, C. J. C., \& Fauchereau, N. (2010). Tropical-extratropical interactions over southern Africa: Three cases of heavy summer season rainfall. Monthly weather review, 138(7), 2608-2623.

[31] De Vries, A. J., Tyrlis, E., Edry, D., Krichak, S. O., Steil, B., \& Lelieveld, J. (2013). Extreme precipitation events in the Middle East: dynamics of the Active Red Sea Trough. Journal of Geophysical Research: Atmospheres, 118(13), 7087-7108.

[32] Martius, O., Sodemann, H., Joos, H., Pfahl, S., Winschall, A., Croci-Maspoli, M., ... \& Sedláček, J. (2013). The role of upper-level dynamics and surface processes for the Pakistan flood of July 2010. Quarterly Journal of the Royal Meteorological Society, 139(676), 1780-1797.

[33] Dee, D.P.; Uppala, S.M.; Simmons, A.J.; Berrisford, P.; Poli, P.; Kobayashi, S.; Andrae, U.; Balmaseda, M.A.; Balsamo, G.; Bauer, P.; et al. The ERA-interim reanalysis: Configuration and performance of the data assimilation system. Q. J. R. Meteorol. Soc. 2011, 137, 553-597.

[34] O'Brien, J. J. (1970). Alternative solutions to the classical vertical velocity problem. Journal of Applied Meteorology, 9(2), 197-203.

[35] Smith, P. J. (1969). On the contribution of a limited region to the global energy budget. Tellus, 21(2), 202-207.

[36] Smith, P. J. (1973). The kinetic energy budget over North America during a period of major cyclone development. Tellus, 25(5), 411-423.

[37] Ward, J. H., \& Smith, P. J. (1976). A kinetic energy budget over North America during a period of short synoptic wave development. Monthly Weather Review, 104(7), 836-848.

[38] Abdeldym, A., Basset, H. A., Sayad, T., \& Morsy, M. (2019). Kinetic energy budget and moisture flux convergence analysis during interaction between two cyclonic systems: Case study. Dynamics of Atmospheres and Oceans, 86, 73-89.

[39] Budyko, M. I., Miller, D. H., \& Miller, D. H. (1974). Climate and life (Vol. 508). New York: Academic press.

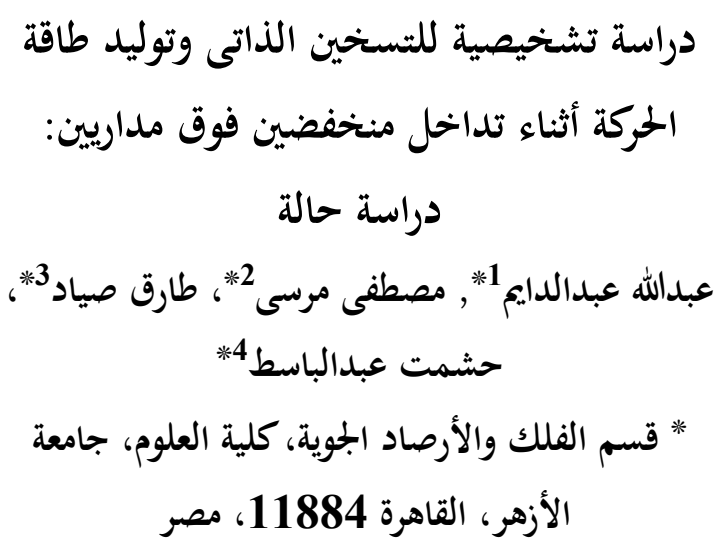

